\title{
The Coincidentalist Reply to the No-Miracles Argument
}

Abstract: Proponents of the no-miracles argument contend that scientific realism is "the only philosophy that doesn't make the success of science a miracle.” Bas van Fraassen argued, however, that the success of our best theories can be explained in Darwinian terms - by the fact they are survivors of a winnowing process in which unsuccessful theories are rejected. Critics of this selectionist explanation complain that while it may account for the fact we have chosen successful theories, it does not explain why any particular one of those theories succeeds. Against this I defend the claim that if selectionists manage to account for the former, they have no burden to account for the latter; the success of any particular one of our best theories might as well be an extraordinary coincidence. I refer to this enhanced selectionist reply as "coincidentalism" and argue that it is a serious but underappreciated response to the no-miracles argument. More generally, I argue the considerations raised in favor of this response show that versions of the no-miracles argument focusing on the success of particular theories are misguided.

\section{Introduction}

Scientific realism is the view that our best scientific theories are true, approximately true, or endowed with some other importantly truthlike property. Proponents of the "no-miracles argument" for scientific realism contend that realism is "the only philosophy that doesn't make the success of science a miracle" (Putnam 1975, p. 73). As is sometimes pointed out, this claim is ambiguous. ${ }^{1}$ On the one hand, it can be construed as the claim that realism is the only

\footnotetext{
${ }^{1}$ See (Barnes 2002, pp. 97; 2008, pp. 138-139), (Busch 2008), (Laudan 1984, p. 92), and (Park 2014, pp. 264-265).
} 
philosophy that adequately explains why science is so good at selecting empirically successful theories. On the other, it can be construed as the claim that realism is the only philosophy that adequately explains why the particular theories we do have (those very ones) are successful. ${ }^{2}$ If the central claim underlying the no-miracles argument is construed in the former way, it becomes what E.C. Barnes (2002) has referred to as "the miraculous choice argument." If it is construed in the latter way, it becomes what Barnes has referred to as "the miraculous theory argument" (pp. 97-98). ${ }^{3}$

It is helpful to keep these distinctions in mind when considering the following wellknown reply to the no-miracles argument introduced by Bas van Fraassen (1980, pp. 39-40):

The Darwinist says: Do not ask why the mouse runs from its enemy. Species which did not cope with their natural enemies no longer exist. That is why there are only ones who do. In just the same way, I claim that the success of current scientific theories is no miracle. It is not even surprising to the scientific (Darwinist) mind. For any scientific theory is born into a life of fierce competition, a jungle red in tooth and claw. Only the successful theories survive - the ones which in fact latched on to the actual regularities in nature.

In short, what explains the fact that our best theories are successful is that those theories are the survivors of a winnowing process, one in which unsuccessful theories are rejected.

\footnotetext{
${ }^{2}$ Here the central claim behind the no-miracles argument is being glossed as one about explanation. But as an anonymous referee points out, an alternative way to construe it is as a claim about probability, as the claim that scientific realism is the only philosophy that does not make the success of science enormously improbable. For more on the relationship between explanatory and probabilistic formulations of the no-miracles argument, see Section 3 (and especially note 14).

${ }^{3}$ See also (Barnes 2008, pp. 138-139).
} 
Following K. Brad Wray (2007; 2010), I will refer to this way of explaining the success of science as "selectionism." Some complain that while selectionism may offer a satisfactory account of why we possess empirically successful theories, it fails to explain, for any given particular theory, why that theory is successful. ${ }^{4}$ Or, to put it another way, while selectionism might offer a satisfactory response to the miraculous choice argument, it fails to offer a satisfactory response to the miraculous theory argument.

Jarrett Leplin (1997, p. 9) provides a useful analogy to illustrate the force of this objection.

To explain why the Wimbledon finalists are so great, it is perfectly appropriate to cite the stringency of the selection procedures for entry into the tournament ... It is hardly surprising that the finalists are great players, considering what they had to go through to get there. However, none of this explains why these particular individuals, who happen to be the finalists ... are so great. On the contrary, it is their being great that explains their having managed to survive the rigors of selection... Analogously, to explain why the theories that we select are successful, it is appropriate to cite the stringency of our criteria for selection. But to explain why particular theories, those we happen to select, are successful, we must cite properties of them that have enabled them to satisfy our criteria.

In the same vein, Philip Kitcher (1993, p. 156) complains that Van Fraassen's Darwinian account remains at "a relatively shallow level of Darwinian explanation." He notes that Darwinists do not merely seek to explain "the presence of certain species ... by noting that the

${ }^{4}$ See (Kitcher 1993, pp. 155-157), (Kukla 1996a, p. S299), (Leplin 1997, pp. 8-9), (Lipton 1994, pp. 100; 2004, pp. 193-195), (Musgrave 1988, p. 242), (Park 2014, pp. 265-266), (Psillos 1999, pp. 96-97), and (White 2003, pp. 678-679). 
organisms belonging to them have high fitness in the relevant environments." Rather,

"Darwinists want to know, at whatever level of generality is possible, what kind of organismenvironment relationships confer reproductive success." Similarly, Kitcher asserts, it is shallow to "explain the endurance and current presence of theories which appear successful by remarking that those which did not have high explanatory and predicative power tended to be discarded." Rather, he contends, we should "ask what it is about those theories that are explanatorily and predictively successful ... that makes for their explanatory and predictive success. ${ }^{\prime 5}$

Since the charge here is that selectionism fails to explain the success of particular theories, I will refer to this criticism as the "missing explanation objection." Some antirealists have (in effect) conceded this point. ${ }^{6}$ As P. Kyle Stanford (2000, p. 260 n.2) points out, even Van Fraassen introduces his Darwinian explanation only after having addressed the issue of why our particular best theories are successful. According to Van Fraassen (1980, pp. 23-25), it would be sufficient to explain the empirical success of a theory by appealing to the fact that certain observable regularities hold, regularities in virtue of which that theory is empirically adequate. His appeal to the Darwinian explanation is meant only to account for the fact that we have empirically successful theories (p. 39). Other antirealists have explicitly endorsed the missing explanation objection and gone on to offer their own explanations of why our particular best theories are successful. ${ }^{7}$

Unsurprisingly, realists have found reasons to be dissatisfied with these explanations. Consider, for example, the common antirealist contention that a theory's being empirically

${ }^{5}$ See also (Lipton 1994, p. 100; 2004, p. 194) and (Psillos 1999, pp. 96-97).

${ }^{6}$ Though see Wray (2007; 2010, pp. 371-372), who argues selectionists can provide local explanations of the success of particular theories.

${ }^{7}$ See, for example, (Stanford 2000) and (Lyons 2002). 
successful could be explained by its being empirically adequate (i.e. correct in what it says concerning the observable portion of reality). There are two complaints that realists often make concerning this proposal. Some realists concede that a theory's being empirically adequate would explain why it is empirically successful. Nevertheless, they deny that this provides us with a suitable explanatory stopping point. They claim that a theory's just so happening to be empirically adequate would itself be a miracle, and therefore some further explanation of that fact would be required. ${ }^{8}$ Other realists complain that appealing to the property of empirical adequacy in order to explain empirical success is circular. They claim these properties are so intimately connected that to explain empirical success in terms of empirical adequacy is tantamount to appealing to empirical success in order to explain itself. ${ }^{9}$ Similar complaints have been lodged against other antirealist views. ${ }^{10}$ I won't attempt to evaluate the cogency of these objections. Nor will I attempt to evaluate various other extant replies to the miraculous theory argument. Instead I want to put forward an altogether different kind of antirealist response to the missing explanation objection.

Let's say that an antirealist proposal provides us with an "adequate explanation" of the success of a scientific theory only if that proposal does not make its success out to be a mere coincidence, is non-circular, and serves as a suitable explanatory stopping point. The kind of antirealist I have in mind concedes (at least for the sake of argument) that there is no adequate antirealist explanation of why our particular best scientific theories are successful. She grants realist criticisms of explanations that appeal to properties such as empirical adequacy and the 152).

${ }^{8}$ See (Leplin 1997, pp. 23-24), (Musgrave 1988, p. 242), (Psillos 1999, p. 93), and (Smart 1968, p. 150-

${ }^{9}$ See (Leplin 1987, p. 520), (Lipton 1994, p. 99), and (Psillos 1999, pp. 92-93).

${ }^{10}$ See (Leplin 1987; 1997, pp. 26-28) and (Musgrave 1988, p. 244), for example, for similar complaints directed against surrealist views (roughly, views according to which the non-observable portion of the world is such as to make the observable portion behave as if the theories in question were true). 
like. Nevertheless, she denies that the debate is to be conceded to the realist on those grounds. Rather, taking herself to have a successful selectionist response to the miraculous choice argument, she also takes herself legitimately to dismiss the explanatory demand underlying the miraculous theory argument. For all the explanatory burdens placed on her for the purpose of answering the no-miracles argument, she contends, it might just as well be an extraordinary coincidence that any particular one of our theories succeeds.

I refer to this way of filling out the selectionist response as "coincidentalism," and I will argue that it is a serious but overlooked contender in the realism-anti-realism debate. I will also argue that the considerations raised in defense of this response generalize beyond their application to selectionism by showing any focus on the miraculous theory argument to be misguided. To be clear about how I envision the dialectical situation, I do not intend to argue that there is in fact no adequate antirealist explanation of the success of particular theories; nor do I take the coincidentalist to be under any burden to provide an argument for that claim. Rather, the coincidentalist merely concedes that claim to proponents of the missing explanation objection and then goes on to argue that, even so, she still has a successful reply to the miraculous theory argument - not in the sense that she meets its explanatory demand, but in the sense that she shows why it need not be met. There are a few precedents to what I am calling "coincidentalism," but to the best of my knowledge, no one has developed this response in quite the way I intend.

Karl Popper (1979), for example, who also endorses a Darwinian analogy regarding the competition between scientific theories, maintains that "no theory of knowledge should attempt to explain why we are successful in our attempts to explain things" (p. 23). But Popper's claim is that no theory of knowledge should attempt to explain why it is that we have managed to come 
across successful theories. The coincidentalist, by contrast, does not deny that we should attempt to explain this general fact. Rather, her claim is that having an explanation of the general fact that science manages to select successful theories alleviates us of the burden of having to explain why particular theories succeed.

Van Fraassen (1980, pp. 23-25) argues that even realists must concede that not all regularities have an explanation. For this reason, he contends, it is legitimate for antirealists to maintain it is merely a brute fact that certain observable regularities hold (regularities in virtue of which a given theory is empirically successful). This response differs from what I am calling “coincidentalism," however, since Van Fraassen does take there to be an adequate explanation for why a given theory is successful. It is because certain observable regularities hold. What is being denied is merely any further burden to account for those regularities.

Larry Laudan (1984) distinguishes the explanatory demand underlying the miraculous theory argument from the one underlying the miraculous choice argument. He sets aside the former on the ground that it is typically not what we are "driving at" (p. 92) when we seek to explain the success of science. As Stanford (2000, p. 271) points out, however, Laudan gives no argument that this demand is illegitimate. The coincidentalist, by contrast, does provide such an argument.

Roger White (2003, pp. 678-680) suggests, in passing, a position that perhaps comes closest to the one I aim to defend. He notes that selectionists might attempt to explain how scientists manage to come up with some successful theories by appealing to the plentitude of attempts. Selectionists might then attribute it to mere luck, he points out, that scientists manage to come up with a successful theory on a certain particular occasion. But here the target explananda pertain to the success of science in selecting empirically successful theories (its 
success in selecting some such theories, and its success in having done so on a particular occasion). In fact, it is White's view that selectionism "carries no force at all" (p. 678) against the miraculous theory argument, since that argument asks not for an explanation of why successful theories were chosen, but for why those theories succeed. The coincidentalist, by contrast, argues that a successful selectionist response to the miraculous choice argument removes the need to provide any such explanation.

Before I develop the coincidentalist reply, I'd like to draw out some of the intuitions that motivate it. I will do so with an analogy. In contrast with the analogies that Leplin and Kitcher provide, it is one in which it is clear that having an explanation for why some item with a given property was selected discharges any further burden to explain why that particular item has that property.

\section{An Analogy}

Imagine I've contacted the company Psychics-R-Us in the hope they will assign me a genuine psychic for the purpose of advising me concerning my upcoming lottery purchases. While I've known for a long time that the non-psychic administrators of Psychics-R-Us sometimes communicate in ways that are misleading, they (fearing legal repercussions) never say anything false. In order to pair me with a putative psychic, they ask me to type a three-digit number (from 000 to 999 ) into their computer system. I comply with their instructions after selecting such a number - 137 - by means of a random number generator. A putative psychic, Clara, quickly responds with the following type-written message: "Your chosen number is 137." The administrators assure me that this message was wholly produced by Clara herself in the absence of any indication of the number I selected. 
At first, I'm quite impressed. I take the fact that Clara accurately reported my number as strong evidence that she has genuine psychic abilities. I soon learn however that Clara was selected out of a pool of 100,000 candidates via the computer system by means of the following procedure: All candidates were independently to type into the system a message of the same format as Clara's, with a report of what they took my number to be. The computer system then filtered out any candidate who reported my number incorrectly and selected from those remaining at random. I am no longer impressed. I now strongly suspect it was just a coincidence that Clara chose my number, a mere lucky guess. The reasoning behind my suspicion is straightforward. Given the existence of so many candidates, it's hardly surprising that some candidates would accurately guess my number. And given the selection procedure, it's guaranteed that if some candidates guessed my number, I would receive a message from one of them.

I inform the administrators of Psychics-R-Us of my reasoning and demand my money back. They concede that, given the size of the candidate pool and the nature of the selection procedure, it is indeed no surprise that a candidate who accurately reported my number was selected. Nevertheless, refusing to refund my money, they argue that I have not explained all one might wish to explain. Sure, they concede, I've managed to explain why some candidate who accurately reported my number was selected. But what I've failed to explain, they argue, is how Clara managed to accurately report my number.

I still want my money back. I grant that it is surprising that Clara herself accurately reported my number. I even grant that if that were the only evidentially relevant proposition I learned, I would have good evidence that Clara has psychic abilities. What I deny is that I have a good overall reason to believe that Clara has psychic abilities given my total evidence. I insist 
that, given my total evidence, it remains reasonable for me to believe it was just a coincidence that Clara managed to accurately report my number.

No doubt the reader has already picked up on how the analogy is supposed to go. Clara's accurately reporting my number corresponds to a particular theory's being empirically successful. Clara's having psychic abilities corresponds to that theory's being true, or approximately true, or having whichever property it is the variety of realism in question would want to claim for it. My initial complaint to the administrators corresponds to the selectionist response to the no-miracles argument. Their reply corresponds to the missing explanation objection. $^{11}$

It is also likely that readers have begun to note several disanalogies between these cases. Clara's accurately reporting my number was a one-off event, whereas our best scientific theories get things right repeatedly. ${ }^{12}$ The hypothesis that Clara got my number right by coincidence affords us with no confidence that she is likely to get things right again, whereas we expect our best scientific theories to continue to get things right. Clara was selected solely on the basis of success that could be judged after the fact, whereas our best scientific theories have been retained not merely because they accommodated previous data, but also because of their ability to generate correct novel predictions. ${ }^{13}$

I don't deny that these disanalogies (and more beside) obtain. In later parts of the paper, I address some of the concerns they raise. Nevertheless, the Psychics-R-Us case does illustrate

\footnotetext{
${ }^{11}$ Similar analogies have been offered elsewhere in connection with the scientific realism debate for different purposes. See for example (Barnes 2008, chapter 5) and (Lipton 1994, p. 105). See Section 5 (especially notes 29 and 32) for further discussion.

${ }^{12}$ Although it is worth noting we could easily modify the case, so it is more analogous to the kind of diachronic testing scientific theories undergo, by imagining the selection occurs over three rounds of elimination, in which I enter my three digits one at a time.

${ }^{13}$ I thank Kevin McCain for pressing me to make explicit note of these disanalogies.
} 
how knowing that a certain type of selection procedure is in place can discharge any further burden to account for the fact that a selected item has a certain property. And I intend to argue that if antirealists can provide a successful selectionist explanation of the success of science, they are in an analogous position with respect to the explanatory demand imposed on them by proponents of the miraculous theory argument.

\section{The Core of the Miraculous Theory Argument}

In order to evaluate the coincidentalist reply, it will prove helpful to employ a framework that allows us to think more formally about relations of confirmation. I find it especially fruitful, in this context, to cast the considerations at issue into the form of arguments pertaining to likelihoods. ${ }^{14}$ Toward that end, allow me to introduce the following notation:

Let's say a theory is "truthlike" if it has whatever truth-related property the realist view in question offers to explain empirical success (whether truth itself, approximate truth, providing an accurate representation of the structures of reality, or some other such property). Now consider some particular theory, $\mathrm{t}$, one that eventually finds its way among our current, best scientific theories (though the fact that $t$ becomes one of our best scientific theories is not included in the background knowledge relative to which the likelihoods in the arguments below are being assessed). Let ' $\mathrm{E}_{t}$ ' stand for the claim that $\mathrm{t}$ is empirically successful and ' $\mathrm{T}_{\mathrm{t}}$ ' for the claim that $\mathrm{t}$ is truthlike. Though we are supposing that $\mathrm{t}$ is ultimately selected by the scientific community, at

\footnotetext{
${ }^{14}$ I acknowledge that not everyone agrees that the best way to reconstruct the no-miracles argument is to employ a probabilistic framework. Some, like Psillos (1999, chapter 9; 2009, chapters 3, 10-11; 2011) for example, think the argument is best construed as an inference to the best explanation that makes no direct appeal to probabilistic considerations. It should be noted however (as Psillos (2009, chapters 3, 10-11) also does) that explanationist and probabilistic formulations of the no-miracles argument are not mutually exclusive, insofar as one might take explanatory considerations to be relevant to the assignment of probabilities or vice versa. My hope, in any case, is that those who are less enthusiastic about employing a probabilistic framework to think about the nomiracles argument will at least find the reconstructions in this section to be of heuristic value.
} 
least in part because it is empirically successful, neither the fact that $t$ is selected, nor the fact that $\mathrm{t}$ is empirically successful, is to be included in the background knowledge.

I presume that, regardless of whatever else proponents of the miraculous theory argument might wish to establish, a central component of their agenda will be to argue that the empirical success of a given theory ( given the above stipulations, I propose, as a first pass, that we represent the core of the miraculous theory argument as follows:

(MT1) $\mathrm{P}\left(\mathrm{E}_{\mathrm{t}} \mid \mathrm{T}_{\mathrm{t}}\right)$ is quite high.

(MT2) $\mathrm{P}\left(\mathrm{E}_{\mathrm{t}} \mid \sim \mathrm{T}_{\mathrm{t}}\right)$ is quite low.

Therefore, $\mathrm{E}_{\mathrm{t}}$ strongly confirms $\mathrm{T}_{\mathrm{t}}$.

Note that I have construed the core of the miraculous theory argument as a likelihood argument for the claim that t's empirical success strongly confirms the proposition that $\mathrm{t}$ is truthlike, and not as an argument that $t$ is probably truthlike. ${ }^{15}$ As is well known, some probabilistic formulations of the no-miracles argument are invalid because they commit the base rate fallacy. This formulation of the core of the miraculous theory argument, which is valid given various standard measures of confirmation, avoids that problem. ${ }^{16}$

\footnotetext{
${ }^{15}$ I am assuming that the relation of confirmation referred to in the conclusion of this argument is one that holds (relative to the background knowledge) independently of whether $\mathrm{E}_{\mathrm{t}}$ is the case. Thus I add no premise reporting that $\mathrm{E}_{\mathrm{t}}$ is true.

${ }^{16}$ See (Howson 2000, pp. 52-59; 2013), (Lipton (2004, pp. 196-198), and (Magnus and Callender 2004). The possibility of avoiding the base rate fallacy by reformulating the no-miracles argument as a likelihood argument is broached by Magnus and Callender (2004, p. 330), who note that such an argument cannot be used to establish the conclusion that the realist's view is probably true. Howson (2013) also criticizes a reformulation of the no-miracles argument along similar lines proposed by Psillos (2009, pp. 66-68), though (as pointed out in note 14) Psillos himself prefers a non-probabilistic formulation of the no-miracles argument.
} 
Granted, this "core" argument does not constitute a fully developed case for realism about $\mathrm{t}$, since it fails to establish that $\mathrm{t}$ is probably truthlike. All it is alleged to establish regarding $\mathrm{t}$ is that $\mathrm{E}_{\mathrm{t}}$ counts (in some important sense) as strong evidence for the claim that $\mathrm{t}$ is truthlike. Even so, proponents of the miraculous theory argument are already in trouble if they cannot establish even that much. And proponents of selectionism might be thought of as attempting to resist even this minimal conclusion. They maintain it isn't the least bit surprising, given what we know about the process of theory selection, that we have come to be in possession of empirically successful theories.

It is also at just this point where the missing explanation objection might be thought to come into play. Let ' $\mathrm{W}$ ' stand for a claim reporting that scientific theories are selected by means of a winnowing process in which unsuccessful theories are discarded in favor of successful ones, along with any other relevant information about the nature of the selection process, though not any information concerning which particular theories are selected. Even if we take $\mathrm{W}$ into consideration (by treating it as if it were an item of background knowledge), the proponent of the missing explanation objection may still point out that the following likelihood argument appears sound:

(ME1) $\mathrm{P}\left(\mathrm{E}_{\mathrm{t}} \mid \mathrm{T}_{t} \& \mathrm{~W}\right)$ is quite high.

(ME2) $\mathrm{P}\left(\mathrm{E}_{\mathrm{t}} \sim \mathrm{T}_{\mathrm{t}} \& \mathrm{~W}\right)$ is quite low.

Therefore, $\mathrm{E}_{\mathrm{t}}$ strongly confirms $\mathrm{T}_{\mathrm{t}}$.

So, the proponent of the missing explanation objection maintains, taking into account what we know about the nature of the selection process does nothing to undermine the core of the miraculous theory argument. 
The coincidentalist, however, refuses to concede this objection. She does not (or at least need not) deny that the above likelihood argument is sound. What she does deny is that it serves as a proper guide to how we should update our credences. By analogy with the Psychics-R-Us case, she reminds us that, when it comes to updating our credences, we need to pay attention to our total evidence. And part of what we learn in this case is not merely that $t$ is empirically successful, but also that $t$ was selected by means of the process reported by W. ${ }^{17}$ And once we recognize this, the coincidentalist claims, we are in a position to see that the miraculous theory argument fails to undermine the antirealist's position.

The proponent of the missing explanation objection might not be so easily dissuaded however. Let ' $\mathrm{S}_{\mathrm{t}}$ ' stand for the proposition that $\mathrm{t}$ was selected, among a relevant class of competitors, on the occasion of theory choice in question, by means of the process reported by $\mathrm{W}$. Note that, given how ' $\mathrm{W}$ ' is defined above, $\mathrm{S}_{\mathrm{t}}$ implies $\mathrm{E}_{\mathrm{t}}$ (but not vice versa), and so $\mathrm{S}_{\mathrm{t}}$ is the logically stronger of the two propositions. Accordingly, the proponent of the missing explanation objection might concede that the principle of total evidence requires us to focus on $S_{t}$ rather than $\mathrm{E}_{\mathrm{t}}$ when considering how we should update our credences. Even so, she might argue, we still find ourselves with a sound version of the core of the miraculous theory argument, one that might be presented as follows:

$(\mathrm{ME} 1 *) \mathrm{P}\left(\mathrm{S}_{\mathrm{t}} \mid \mathrm{T}_{\mathrm{t}} \& \mathrm{~W}\right)>\mathrm{P}\left(\mathrm{S}_{\mathrm{t}} \mid \sim \mathrm{T}_{\mathrm{t}} \& \mathrm{~W}\right)$.

Therefore, $\mathrm{S}_{\mathrm{t}}$ strongly confirms $\mathrm{T}_{\mathrm{t}}$.

${ }^{17}$ See White's (2000) discussion on the importance of following the principle of total evidence by attending to the strongest, evidentially relevant proposition learned, in contexts in which one case is being singled out from a potentially large number. 
She can point out that even taking into consideration all we know about the nature of the selection process, there is good reason to believe the inequality mentioned in ME1* holds. Since the selection process screens out any theory that is not empirically successful, it is reasonable to believe that $\mathrm{t}$ is much more likely to be selected given any assumption that guarantees or makes highly likely that it is among the empirically successful candidates. And we may grant the realist for the sake of argument that the claim that $\mathrm{t}$ is truthlike is such an assumption. ${ }^{18}$

Suppose then we concede to the realist that the above argument is sound. Even so, the Psychics-R-Us analogy should make us suspicious of the claim that it ought to move us toward the position that whichever theory gets selected on the occasion in question is truthlike (even in the modest sense of causing us to shift our credences by a significant factor). Plausibly, it is much more likely that Clara would be among the small group of candidates who got my number right, and thus much more likely that she would be selected, on the assumption that she does have genuine psychic abilities, than on the assumption that she does not. Nevertheless, given my knowledge of the size of the candidate pool and the nature of the selection procedure, it does not seem that this consideration affords me with strong evidence for the claim that whoever was selected has genuine psychic abilities.

In the remaining sections, I explore this analogy in more detail while supplementing it with various formal considerations. On that basis, I argue that if the selectionist does in fact have a successful response to the miraculous choice argument, she also has a successful response to the miraculous theory argument. This suffices to answer the missing explanation objection. Along the way, I also explore and respond to the objection that the phenomenon of novel

\footnotetext{
${ }^{18}$ Though see (Laudan 1981) and (Lyons 2002, pp. 899-900).
} 
prediction undermines the coincidentalist response. Finally, I end by noting how the arguments in this paper also establish that the miraculous theory argument should be abandoned. I conclude that any subsequent debate over the no-miracles argument should be focused entirely on the miraculous choice argument.

\section{From Selectionism to Coincidentalism}

One complaint some realists have concerning the selectionist explanation is that it is one realists themselves could endorse (and therefore not a genuinely competing antirealist explanation). ${ }^{19}$ On one way of developing this criticism, it is just the missing explanation objection. But there are other ways of filling in this complaint. The realist might agree that the selectionist correctly explains why we have successful theories. But she might also maintain that there is a further, realist explanation to be had for why science is so good at selecting such theories; it is because the methods of selection are biased toward truthlike theories.

The selectionist might respond to this criticism by saying it is not her goal to supply an explanation that is inconsistent with realism, merely one that does not presuppose it. But in order to have a successful response to the miraculous choice argument, the selectionist must do more than this. She must also effectively argue that the availability of her proposed explanation makes it reasonable for her not to endorse a realist one. ${ }^{20}$ And this brings with it certain commitments about what it is reasonable to believe concerning the nature of the selection process. As I will now proceed to argue, once these commitments are uncovered, it can be shown that if selectionism provides a successful response to the miraculous choice argument,

\footnotetext{
${ }^{19}$ See (Lipton 1994, pp. 99-100; 2004, pp. 193-195), (Musgrave 1988, p. 242), and (Psillos 1999, pp. 9697) for articulations of this objection. See (Wray 2010, pp. 374-376), however, for an argument that the selectionist explanation does in fact compete with a realist one.

${ }^{20}$ I thank Matthew McGrath for helping me sort through what the dialectical situation looks like here.
} 
then coincidentalism provides a successful response to the miraculous theory argument. I would like to emphasize that my aim in this section is merely to establish this conditional claim. Accordingly, I need only uncover the selectionist's commitments, not defend them.

Let ' $\mathrm{T}_{\mathrm{W}}$ ' stand for the claim that whichever particular theory (if any) among the relevant class of competitors that gets selected, on the occasion of theory choice we've been considering, by means of the process reported by $\mathrm{W}$, is truthlike. The selectionist is committed to the claim that it is consistent with all she reasonably believes that, generally speaking, the probability of the selection process resulting in a theory that is not truthlike, on a typical occasion, is high, or at least not too low. Thus, concerning the case at hand, she is committed to the claim that it is consistent with all she reasonably believes that $\mathrm{P}\left(\sim \mathrm{T}_{\mathrm{W}} \mathrm{lW}\right)$ isn't low. ${ }^{21}$ There are at least two ways, furthermore, in which this probability might end up low. One has to do with the nature of the candidate pool, the other with the nature of the selection process.

Since the selection process screens out all the candidates that are not empirically successful, call all the ones that are successful the "viable candidates." One way $\mathrm{P}\left(\sim \mathrm{T}_{\mathrm{W}} \mathrm{lW}\right)$ might end up low is if all the viable candidates are truthlike, or at least if a high proportion of them are. If the candidate pool is like that, then there may be a high probability that either no candidate gets selected (if it is vacuously true that all the viable candidates are truthlike on account of there being no viable candidates) or that a truthlike one does (note that if no candidate gets selected then $\mathrm{T}_{\mathrm{W}}$ is trivially true $)$. Another way $\mathrm{P}\left(\sim \mathrm{T}_{\mathrm{W}} \mathrm{lW}\right)$ might end up low is if the selection process is strongly biased toward truthlike theories. The selectionist is, therefore,

\footnotetext{
${ }^{21}$ She is committed to this, at least, provided that she has no background information indicating that the occasion of theory choice in question is somehow atypical. And since the intention is to consider a typical case, we may regard this proviso as met.
} 
committed to its being consistent with all she reasonably believes that $\mathrm{P}\left(\sim \mathrm{T}_{\mathrm{W}} \mathrm{IW}\right)$ isn't low for either of the above reasons.

It may also be that it is consistent with all the selectionist reasonably believes that $\mathrm{P}\left(\sim \mathrm{T}_{\mathrm{W}} \mid \mathrm{W}\right)$ isn't low because the selection process is strongly biased against truthlike theories. If this possibility obtains, the selectionist clearly has no additional burden to reply to the miraculous theory argument. On the contrary, if this possibility obtains, then it is consistent with everything the selectionist reasonably believes that the fact that $\mathrm{t}$ (the particular theory that wound up being selected on the occasion in question) was chosen actually disconfirms the realist's explanation of t's success. The claim that the selection process is strongly biased against truthlike theories in this way is inconsistent, however, with a claim that was already granted to the realist for the sake of argument - namely, that $\mathrm{P}\left(\mathrm{S}_{\mathrm{t}} \mid \mathrm{T}_{\mathrm{t}} \& \mathrm{~W}\right)>>\mathrm{P}\left(\mathrm{S}_{\mathrm{t}} \mid \sim \mathrm{T}_{t} \& \mathrm{~W}\right)$. Accordingly, let's set aside this possibility.

Given all the above, the selectionist is committed to its being consistent with all she reasonably believes that, on a typical occasion of theory choice, there is an abundance of empirically successful theories that are not truthlike in the candidate pool, and that if there are truthlike theories among the viable candidates, the selection process is not strongly biased toward those theories. One might wonder whether these are plausible commitments.

The history of science, the realist might object, seems to tell a different story. Often a theory was selected, not out of a large pool of competitors, but out of a small one, or even because it was the only available option. Here the selectionist can simply admit, however, that scientists often have only a small number of successful candidates to choose from given the totality of their criteria for theory selection. But some of these criteria include various superempirical virtues (such as simplicity, fruitfulness, and the like). And while realists might want to 
insist that these super-empirical virtues are conducive to the selection of truthlike theories (i.e. that they are epistemic and not merely pragmatic or aesthetic), that is not a claim to which they are entitled in the current debate (not if they want to avoid begging the question).

What the selectionist requires, furthermore, is merely that it be consistent with all she reasonably believes that there are many successful candidates once such extra-empirical criteria are set aside. And here she might appeal to more or less standard underdetermination considerations in order to argue that this is the case. Granted, there is an ongoing debate about whether these considerations do in fact secure the kind of diversity the selectionist requires. ${ }^{22}$ But since my goal here is merely to uncover the selectionist's commitments rather than defend them, I need not attempt to add to that discussion.

In any case, given these commitments, the proponent of the selectionist response to the miraculous choice argument is also committed to the claim that, when it comes to the miraculous theory argument, her epistemic situation is, in an interesting way, analogous to the situation in which I find myself in the Psychics-R-Us case. In the latter situation, it was also consistent with all I reasonably believed that there were multiple non-psychic candidates in the pool who accurately reported my number, and that the selection process was not strongly biased toward psychic candidates. It is in light of these commitments that the coincidentalist, who takes herself to have a successful selectionist response to the miraculous choice argument, also takes herself to have a successful response to the miraculous theory argument.

Fortunately, it is also the case that we need not rely solely on analogy, but can turn directly to formal considerations. If the coincidentalist's epistemic situation is in fact as the

\footnotetext{
${ }^{22}$ For some of this debate, see (Dellsen forthcoming), (Earman 1993), (Kukla 1996b; 2001), (Laudan and Leplin 1991), (Stanford 2001; 2006), (Tulodziecki 2012; 2013), and (Worrall 2011).
} 
selectionist requires, then she need not deny that $\mathrm{P}\left(\mathrm{S}_{\mathrm{t}} \mid \mathrm{T}_{\mathrm{t}} \& \mathrm{~W}\right)>\mathrm{P}\left(\mathrm{S}_{\mathrm{t}} \mid \sim \mathrm{T}_{t} \& \mathrm{~W}\right)$, and therefore that $\mathrm{S}_{\mathrm{t}}$ strongly confirms $\mathrm{T}_{\mathrm{t}}$. She can also point out, however, that when assessing what learning $\mathrm{S}_{\mathrm{t}}$ makes it reasonable for us to believe, it is helpful to consider the impact that discovering $\mathrm{S}_{\mathrm{t}}$ has on our credences regarding $\mathrm{T}_{\mathrm{W}}$, and not merely those regarding $\mathrm{T}_{\mathrm{t}}$. In order to see this, recall that ' $\mathrm{S}_{\mathrm{t}}$ ' stands for the proposition that $\mathrm{t}$ was selected, among a relevant class of competitors, on the occasion of theory choice in question, by means of the process reported by $\mathrm{W}$, and that ' $\mathrm{T}_{\mathrm{W}}$ ' stands for the claim that whichever particular theory (if any) among the relevant class of competitors that gets selected, on that occasion, by means of the process reported by $\mathrm{W}$, is truthlike. Accordingly, the conjunction of $S_{t}$ and $T_{t}$ implies $T_{W}$, and likewise the conjunction of $\mathrm{S}_{\mathrm{t}}$ and $\mathrm{T}_{\mathrm{W}}$ implies $\mathrm{T}_{\mathrm{t}}$. Thus, $\mathrm{P}\left(\mathrm{T}_{\mathrm{t}} \mid \mathrm{S}_{\mathrm{t}} \& \mathrm{~W}\right)=\mathrm{P}\left(\mathrm{T}_{\mathrm{W}} \mid \mathrm{S}_{\mathrm{t}} \& \mathrm{~W}\right)$. Therefore, if it remains reasonable not to believe $T_{W}$ upon learning $S_{t}$, it also remains reasonable not to believe $T_{t}$.

So how should learning $S_{t}$ affect our credence regarding $T_{W}$ ? There is, in fact, a good case to be made that $T_{\mathrm{W}}$ doesn't render $\mathrm{S}_{\mathrm{t}}$ any more expectable, and therefore learning $\mathrm{S}_{\mathrm{t}}$ shouldn't cause us to raise our credence in Tw at all. That is, there is a good case to be made that $\mathrm{P}\left(\mathrm{S}_{\mathrm{t}} \mid \mathrm{Tw} \& \mathrm{~W}\right) \leq \mathrm{P}\left(\mathrm{S}_{\mathrm{t}} \mid \mathrm{W}\right)$. That's because, absent any special information beforehand indicating that $\mathrm{t}$ is truthlike, there is no more reason to believe that $\mathrm{t}$ is one of the truthlike theories than there is to believe that it is not. So the probability that $\mathrm{t}$ would be selected on the assumption that whichever theory is selected is truthlike is at least no greater than the probability that $\mathrm{t}$ would be selected absent that assumption. So, supposing the coincidentalist is right to maintain that it is reasonable for her not to believe Tw prior to learning $S_{t}$, it remains reasonable for her not to believe $T_{w}$ after learning $S_{t}$.

Note that the coincidentalist's response here goes well beyond making the negative observation that the core of the miraculous theory argument fails to establish that the particular 
theory selected on the occasion in question is probably truthlike. Rather, the coincidentalist argues positively that the kind of evidence cited by proponents of the miraculous theory argument need not even so much as shift her credences toward the position that whichever theory was selected is truthlike. ${ }^{23}$ Indeed, if one identifies the realist hypothesis concerning the case at hand with $\mathrm{T}_{\mathrm{W}}$, then the coincidentalist is mounting a positive argument for the conclusion that the kind of evidence cited by proponents of the miraculous theory argument fails to confirm the realist hypothesis at all. ${ }^{24}$

No doubt some realists will object to the claim that there is no information beforehand indicating that $\mathrm{t}$ is truthlike. That's because scientists don't merely select theories on the basis of whether they are empirically successful, but also on the basis of how well they fit with previously established theories, as well as the extent to which they exemplify the various superempirical virtues. The coincidentalist can appropriately dismiss this objection however. She may grant that a theory's fitting with other truthlike theories provides some reason to believe that it is also truthlike. Even so, a theory's fitting with previously established theories gives us strong reason to believe it is truthlike only if we have good reason to believe the previously established theories are themselves truthlike, a claim to which the realist is not entitled in the current

${ }^{23}$ Note again that this is all compatible with its being the case that $S_{t}$ confirms $T_{t}$ and even with its being the case that $\mathrm{S}_{\mathrm{t}}$ confirms that a truthlike theory gets selected on the occasion in question. The coincidentalist's conclusion is not that learning $S_{t}$ need not cause her to raise her credence in either of these claims. Rather, it is that learning $S_{t}$ need not cause her to raise her credence in either of them above the credence she assigns to $T_{w}$, which she does maintain is not confirmed by $\mathrm{S}_{\mathrm{t}}$, and which she takes herself to reasonably fail to believe.

${ }^{24} \mathrm{I}$ take it that the realist hypothesis concerning the case at hand should not be identified with $\mathrm{T}_{\mathrm{t}}$, since one ought to be able to hold the realist hypothesis regarding whichever theory is selected prior to learning $\mathrm{S}_{\mathrm{t}}$. One might reject the identification of the realist hypothesis with Tw on the grounds that it should be construed as the hypothesis that some truthlike theory is selected on the occasion in question, whereas Tw does not imply this (since as previously noted $\mathrm{T}_{\mathrm{W}}$ can be vacuously true). But my view is that the realist hypothesis should be construed so as to allow for the possibility that, because the methods of selection are disposed to choose only truthlike theories, and no such theories are forthcoming, no theory is selected. Nothing pertaining to the substance of my argument turns on this identification however. 
dialectical context. ${ }^{25}$ And a theory's exemplifying various super-empirical virtues gives us good reason to believe that it is truthlike only if those virtues are themselves conducive to the selection of truthlike theories - that is, only if they are epistemic virtues and not (as antirealists are apt to maintain) merely pragmatic or aesthetic ones. As previously noted, however, the claim that these virtues are epistemic is not one to which the realist is entitled in the current debate, since the very thing at issue is whether we have good reason to believe that the criteria and methods of science are disposed to yield truthlike theories.

The coincidentalist concedes that, in some ways, it is surprising that a given particular one of our best theories succeeds. She concedes, with respect to any given one of those theories, that if in fact there is no adequate explanation for that theory's success, then its success is an extraordinary coincidence. She is also willing to grant (at least of the sake of argument) that there is no such explanation. She denies, however, that these facts provide any good reason to doubt her antirealist position.

\section{An Objection: What About Novel Prediction?}

One fact that might be thought to undermine the coincidentalist's position, however, is that our current best theories have not been retained merely because they successfully accommodated various data, but also because they made successful novel predictions. And it might be thought implausible that our current best theories would have this feature if their empirical success were simply a matter of coincidence. Indeed, most sophisticated, contemporary developments of the

${ }^{25}$ The criterion that new theories fit with successful background theories plays a prominent role in versions of the no-miracles argument put forward by Boyd (1985), Psillos (1999, chapter 4; 2011), and Barnes (2008, chapter 4). I thank André Ariew for pressing me to consider this point. 
no-miracles argument explicitly build into the explanandum the datum that our current best theories have generated correct novel predictions. ${ }^{26}$

A moment's reflection reveals, however, that if this objection is to have any force, it must be directed against the coincidentalist's reply to the miraculous choice argument and not her reply to the miraculous theory argument. To see this, suppose, just for the moment, that the coincidentalist does have a successful selectionist reply to the miraculous choice argument, one that holds up in light of the novel success of scientific theories. The considerations rehearsed above show that in order for that to be the case, it must be consistent with all the coincidentalist reasonably believes that the probability of the process of theory selection resulting in theories that are not truthlike is high or at least not too low. And those same considerations also show that if that is so, the coincidentalist can legitimately dismiss the explanatory demand afforded her by the miraculous theory argument. The structure of the dialectic, as far as it pertains to the coincidentalist's reply to the miraculous theory argument, does not change merely because a theory's having made correct novel predictions is now built into the criteria for empirical success.

Since this objection threatens the coincidentalist's reply to the miraculous choice argument, furthermore, rather than her reply to the miraculous theory argument, strictly speaking, it affords no objection to the conditional claim that I've been defending: If selectionism provides a successful response to the miraculous choice argument, then coincidentalism provides a successful response to the miraculous theory argument. Even so,

${ }^{26}$ See (Barnes 2002, p. 99; 2008, pp. 128-132), (Leplin 1997), (McCain 2016, chapter 14), (Musgrave 1988, pp. 231-233), (Psillos 2009, p. 48), and (White 2003, p. 677). 
since I would like to put forward coincidentalism as a plausible contender in the debate, I am under some burden to reply.

When assessing the impact of successful novel prediction on the plausibility of the coincidentalist's selectionist reply to the miraculous choice argument, it is important to focus on just which fact about theory choice she is alleged to have difficulty explaining. Suppose, for example, that the challenge put to the coincidentalist is merely to account for the fact that all of our current best theories have an impressive track record of having made successful novel predictions. In that case, the coincidentalist will rightfully maintain that we should regard the entire history of testing these theories (including the testing of their novel predictions) as part of the environment in which they have had to survive in order to have made it this far - as part of their "life of fierce competition" in "a jungle red in tooth and claw." But if that is how we are to regard things, the fact that our best scientific theories have made correct novel predictions is built into the criteria of success, and the coincidentalist's explanation of why it is that all our current best theories have met those criteria is, simply, "only the successful theories survive."

A more forceful way of pressing this objection involves looking not merely at the fact that our current best theories have been vindicated in their novel predictions, but at the rate at which scientists have initially adopted theories that subsequently went on to make successful novel predictions. James Robert Brown (1985, p. 1139) contends, for example, that the theories scientists adopt "make correct [novel] predictions more often than one could expect on the basis of mere chance." Accordingly, he argues, Van Fraassen's "Darwinian analogy breaks down 
since most species could not survive a radical change of environment, the analogue of the novel prediction." 27

At this point, the coincidentalist might challenge the claim that the rate at which the scientific community has initially adopted novelly successful theories exceeds what we would expect due to chance. ${ }^{28}$ We must count up not only previous successes, but also previous failures. Often past theories have been rejected precisely because their novel predictions failed to pan out; perhaps we should not be surprised that a large number of failed attempts were accompanied by a few successful ones. ${ }^{29}$ It is also not clear, furthermore, that a realist explanation of the novel successes we are aware of is to be preferred in the absence of alternatives. As Wray (2007, p. 88; 2010, p. 372) argues, the selectionist might point to examples in the history of science where it seems that theories which were not even approximately true nevertheless generated correct novel predictions. ${ }^{30}$

But suppose we grant that the rate at which the scientific community has adopted theories leading to correct novel predictions does exceed what we would expect due to chance and that a realist explanation is to be preferred in the absence of plausible alternatives. This does not afford us with a decisive objection to coincidentalism. Remember, the coincidentalist (given what she grants to the realist) is committed to the claim that there is no adequate antirealist explanation for the success of particular theories; she is not, however, committed to the claim that there is no

${ }^{27}$ See also (Boyd 1985, pp. 23-28).

${ }^{28}$ See (Barnes 2002, p. 100; 2008, p. 143) concerning the crucial role this claim plays in the miraculous choice argument.

${ }^{29}$ Barnes (2008, chapter 5) uses examples similar to my Psychics-R-Us case in order to illustrate how knowledge of there having been a large number of attempts at prediction can undermine the epistemic significance of novel predictive success. See also (White 2003, pp. 679-680).

${ }^{30}$ Wray cites Martin Carrier (1991) who points to Priestley's prediction of the reductive properties of hydrogen based on phlogiston theory and Dalton's and Gay-Lussac's prediction of the equality of thermal expansion of all gases based on the caloric theory of heat. 
adequate antirealist explanation for why it is that science has been so good at selecting successful theories.

One way in which the coincidentalist might attempt to explain the latter, furthermore, is by maintaining that the selection process is biased toward some property that correlates with, but does not adequately explain, the novel success of particular theories. Indeed, this is just how selectionist explanations often work. The fact that a given member of the club is rich does not adequately explain why she is a mega-millions lottery winner. Even so, the fact that only the rich are admitted to the club might well adequately explain why the club contains an unusually high number of mega-millions lottery winners. Likewise, perhaps the fact that a given theory is empirically adequate, for example, does not suffice to explain its empirical success (either because such an explanation would be circular or would fail to provide a suitable explanatory stopping point). Nevertheless, the rigors of scientific testing might ensure that theories which are not empirically adequate tend to be quickly discarded before they have a chance to make significant inroads into the scientific community. It may be that, because of this, scientific methodology contains a strong bias toward empirically adequate theories. And this bias might explain why a significant proportion of the theories that are initially adopted by the scientific community go on to make successful novel predictions. ${ }^{31}$

So far we've been considering how the coincidentalist proposes to deal with previously confirmed novel predictions. But there is also a residual issue: Often we appear rationally confident that, were the currently unverified predictions of our best theories tested, they too would be confirmed. And the coincidentalist might be thought to lack the resources to explain

${ }^{31}$ Barnes (2002, pp. 103, 111-113; 2008, pp. 155-160) suggests (but does not himself endorse) an antirealist response to the miraculous choice argument along these lines. White (2003, p. 678) also notes that the antirealist might avail herself of this suggestion. 
this confidence. ${ }^{32}$ One thing that should be pointed out is that perhaps we are not entitled be so confident. The failure of an established theory's previously untested predictions has more than once driven the engines of scientific discovery. Even so, the coincidentalist is not without resources to explain whatever rational confidence we do have. If, for example, she maintains we can rationally take the process of selection to be biased toward empirically adequate theories, she can also explain why we may rationally expect our best theories would withstand further testing. Alternatively, taking a cue from Laudan (1984, pp. 96-102), she might deny the need to explain our rational confidence by making any reference to properties had by theories that correlate with predictive success; rather, she might maintain that the explanation lies entirely within the nature of the testing process. In particular, she might maintain that it lies in the fact that the process by which scientific theories are tested is an especially rigorous one, and this makes our inductive projections to the effect that surviving theories would continue to withstand additional tests especially robust.

In any case, at this point, we have stopped considering the miraculous theory argument and begun focusing on the miraculous choice argument. My contention is that if the antirealist has a successful selectionist response to the miraculous choice argument, then coincidentalism offers a successful response to the miraculous theory argument. I do not claim that the antecedent is true. I do claim, however, that by having established the truth of this conditional, I have shown the missing explanation objection to selectionism to be misguided.

\section{Conclusion: Dispensing with the Miraculous Theory Argument}

${ }^{32}$ Lipton (1994, p. 105) uses an analogy similar to my Psychics-R-Us case to illustrate this point. 
More than that, I also take the considerations raised in this paper to establish another, deeper conclusion. On the one hand, they show that if antirealists have a successful response to the miraculous choice argument, they are in a position to make certain claims about what it is reasonable to believe regarding the probability of a truthlike theory being selected, and are thereby entitled to dismiss the explanatory demand underlying the miraculous theory argument. On the other hand, a successful response to the miraculous theory argument need not constitute a successful response to the miraculous choice argument. Even if a realist explanation isn't required to account for the success of any particular one of our best theories, it doesn't follow that a realist explanation isn't required to account for why science is so good at selecting successful theories. Accordingly, the focus of the debate should not be on the miraculous theory argument. The viability of the antirealist's position turns entirely on her prospects for a successful reply to the miraculous choice argument. ${ }^{33}$

\section{Works Cited}

Barnes, Eric Christian (2008) The Paradox of Predictivism (Cambridge University Press).

- (2002) “The Miraculous Choice Argument for Realism” Philosophical Studies, 111, pp. 97-120.

Boyd, Richard N. (1985) “Lex Orandi est Lex Credendi” in Images of Science edited by Paul M. Churchland and Clifford A. Hooker (The University of Chicago Press), pp. 3-34.

Brown, James Robert (1985) "Explaining the Success of Science." Originally printed in Ratio, 27, pp. 49-66. Reprinted in Philosophy of Science: The Central Issues edited by Martin Curd and J.A. Cover (London: Norton, 1998), pp. 1136-1152.

Busch, Jacob (2008) “No New Miracles, Same Old Tricks” Theoria, 74, pp. 102-114.

Carrier, Martin (1991) "What is Wrong with the Miracle Argument?" Studies in History and Philosophy of Science Part A, 22, pp. 23-36.

\footnotetext{
${ }^{33}$ For helpful comments on previous drafts I would like to thank André Ariew, Sarah Boyce, Marina Folescu, Robert Johnson, Kevin McCain, Matthew McGrath, Andrew Melnyk, Eileen Nutting, Alexandru Radulescu, Paul Weirich, and anonymous referees who provided valuable feedback.
} 
Dellsén, Finnur (forthcoming) "Realism and the Absence of Rivals" Synthese.

Earman, John (1993) “Underdetermination, Realism, and Reason” Midwest Studies in Philosophy, 18, pp. 19-38.

Howson, Colin (2013) "Exhuming the No-Miracles Argument” Analysis, 73, pp. 205-211.

- (2000) Hume's Problem: Induction and the Justification of Belief (Oxford University Press).

Kitcher, Philip (1993) The Advancement of Science: Science without Legend, Objectivity without Illusions (Oxford University Press).

Kukla, André (2001) “Theoreticity, Underdetermination, and Disregard for Bizarre Scientific Hypotheses" Philosophy of Science, 68, pp. 21-35.

- (1996a) "Antirealist Explanations of the Success of Science" Philosophy of Science, 63, pp. S298-S305.

- (1996b) "Does Every Theory Have Empirically Equivalent Rivals" Erkenntnis, 44, pp. 137-166.

Laudan, Larry (1984) "Explaining the Success of Science: Beyond Epistemic Realism and Relativism" in Science and Reality edited by James T. Cushing, Gary Gutting, and C.F. Delaney (Notre Dame: University of Notre Dame Press), pp. 83-105.

- (1981) “A Confutation of Convergent Realism” Philosophy of Science, 48, pp. 19-49.

Laudan, Larry and Leplin, Jarrett (1991) "Empirical Equivalence and Underdetermination" Journal of Philosophy, 88, pp. 449-472.

Leplin, Jarrett (1997) A Novel Defense of Scientific Realism (Oxford University Press).

- (1987) “Surrealism” Mind, 96, pp. 519-524.

Lipton, Peter (2004) Inference to the Best Explanation, second edition (Routledge).

- (1994) "Truth, Existence, and the Best Explanation" in The Scientific Realism of Rom Harre edited by A.A. Derksen (Tilburg: Tilburg University Press), pp. 89-111.

Lyons, Timothy D. (2002) "Explaining the Success of a Scientific Theory" Philosophy of Science, 70, pp. 891-901.

McCain, Kevin Ray (2016) The Nature of Scientific Knowledge: An Explanatory Approach (Dordrecht: Springer). 
Magnus, P.D. and Callender, Craig (2004) "Realist Ennui and the Base Rate Fallacy" Philosophy of Science, 71, pp. 320-338.

Musgrave, Alan (1988) "The Ultimate Argument for Scientific Realism” in Relativism and Realism in Science edited by Robert Nola (Boston: Kluwer Academic Publishers), pp. 229-252.

Park, Seungbae (2014) “On the Evolutionary Defense of Scientific Antirealism” Axiomathes, 24, pp. 263-273.

Popper, Karl R. (1979) Objective Knowledge: An Evolutionary Approach, revised edition (Oxford University Press).

Psillos, Stathis (2011) "The Scope and Limits of the No Miracles Argument" in Explanation, Prediction, and Confirmation edited by Dennis Dieks, Wenceslao J. Gonzalez, Stephan Hartmann, Thomas Uebel, and Marcel Weber (NY: Springer), pp. 2335 .

- (2009) Knowing the Structure of Nature: Essays on Realism and Explanation (Palgrave Macmillan).

- (1999) Scientific Realism: How Science Tracks Truth (Routledge).

Putnam, Hilary (1975) "What is Mathematical Truth" Historia Mathematica, 2, pp. 529-543. Reprinted in Mathematics, Matter and Method by Hilary Putnam (Cambridge University Press, 1979), pp. 60-78.

Smart, J.J.C. (1968) Between Science and Philosophy (NY: Random House).

Stanford, P. Kyle (2006) Exceeding Our Grasp: Science, History, and the Problem of Unconceived Alternatives (Oxford University Press).

- (2001) "Refusing the Devil's Bargain: What Kind of Underdetermination Should We Take Seriously?” Philosophy of Science, 68, pp. S1-S12.

- (2000) "An Anti-Realist Explanation of the Success of Science" Philosophy of Science, 67, pp. 266-284.

Tulodziecki, Dana (2013) "Underdetermination, Methodological Practices, and Realism," Synthese, 190, pp. 3731-3750.

Tulodziecki, Dana (2012) “Epistemic Equivalence and Epistemic Incapacitation” British Journal for the Philosophy of Science, 63, pp. 313-328.

Van Fraassen, Bas (1980) The Scientific Image (Oxford University Press). 
White, Roger (2003) "The Epistemic Advantage of Prediction over Accommodation" Mind, 112, pp. 653-683.

- (2000) "Fine-Tuning and Multiple Universes" Nous, 34, pp. 260-276.

Worrall, John (2011) "Underdetermination, Realism, and Empirical Equivalence" Synthese, 180, pp. 157-172.

Wray, K. Brad (2010) “Selection and Predictive Success” Erkenntnis, 72, pp. 365-377.

- (2007) "A Selectionist Explanation for the Success and Failures of Science" Erkenntnis, 67, pp. 81-89. 